Wisnhu Githa, Ridwan I dan Tanti K, Pengaruh Dan Karakteristik Individu Terhadap Kepuasan Kerja Dan Kinerja Karyawan Perusahaan Daerah Perkebunan Jember

\title{
PENGARUH PELATIHAN DAN KARAKTERISTIK INDIVIDU TERHADAP KEPUASAN KERJA DAN KINERJA KARYAWAN PERUSAHAAN DAERAH PERKEBUNAN JEMBER
}

\author{
(The effect of training and individual characterics on satisfaction and performance of employees of local \\ government owned plantation enterprise Jember)
}

Oleh :

\section{WISNHU GITHA *), RIDWAN ISKANDAR dan TANTI KUSTIARI **)}

\begin{abstract}
ABSTRAK
Penelitian ini bertujuan 1) menganalisis pengaruh pelatihan terhadap kinerja karyawan pada perusahaan daerah pekebunan (PDP) Jember; 2) menganalisis pengaruh pelatihan terhadap kepuasan kerja karyawan PDP Jember; 3) menganalisis pengaruh karaktristik individu terhadap kepuasan kerja karyawan PDP Jember; 4) menganalisis karakteristik individu terhadap kinerja karyawan PDP Jember; 5) menganalisis pengaruh kepuasan kerja terhadap kinerja karyawan PDP Jember. Populasi yang dimaksud dalam penelitian ini adalah seluruh karyawan PDP Jember. Karyawan yang dimaksud dalam populasi ini berjumlah 624 orang. Penelitian ini menggunakan ukuran sampel 160 orang. Metode analisis data menggunakan Structural Equation Model (SEM). Hasil penelitian menunjukkan pelatihan berpengaruh signifikan dan positif terhadap kepuasan kerja karyawan PDP Jember. Pelatihan berpengaruh signifikan dan positif terhadap kinerja karyawan PDP Jember. Karakteristik individu berpengaruh signifikan dan positif terhadap kepuasan kerja karyawan PDP Jember. Karakteristik individu tidak berpengaruh signifikan dan positif terhadap kinerja karyawan PDP Jember, kepuasan kerja berpengaruh signifikan dan positif terhadap kinerja karyawan PDP Jember.
\end{abstract}

Kata kunci: pelatihan, karakteristik individu, kepuasan kerja, kinerja

\section{ABSTRACT}

This study was intended to analyze 1) the effect of training on performance of employees local government-owned plantation enterprise (PDP) Jember; 2) the effect of training on job satisfaction of PDP Jember; 3$)$ the effect of individual characterics on job satisfactin of PDP Jember; 4) the effect of individual characteristics on performance of employees of PDP Jember; 5) the effect of job satisfaction on performance of employees of PDP Jember. The population in this study was all employees of PDP Jember. Employees in this population were 624 in total. This study involved 160 people as samples. The analysis tool used in this study was the Structural Equation Model (SEM). The results showed that training significantly affects on satisfaction and performance of employee, individual characterics significantly affects on satisfaction, but individual characteristics had no significantly effect on employee performance. Job satisfaction significantly effect on performance of employee .

Keywords: training, individual characteristics, job satisfaction, employee performance

\section{PENDAHULUAN}

Peningkatan kinerja karyawan dapat dilakukan dengan memelihara hubungan antar karyawan dalam hal kepuasan kerja, pelatihan dan pengembangan organisasi. Kepuasan kerja yang menyangkut perasaan harus diperhatikan, sebab kepuasan kerja tercermin pada hasil pekerjaan. Pimpinan sebagai manajer dituntut lebih profesional agar mampu menimbulkan kepuasan kerja karyawan.
Suyatno (2002) menyatakan bahwa kinerja (prestasi kerja) adalah hasil yang dicapai seseorang dalam melaksanakan tugas-tugas yang dibebankan kepadanya didasarkan atas kecakapan, pengalaman, kesungguhan serta waktu.

Menurut Simamora (2003) pelatihan merupakan kegiatan untuk meningkatkan pengetahuan umum seseorang termasuk di dalamnya peningkatan penguasaan teori dan ketrampilan memutuskan terhadap persoalanpersoalan yang menyangkut kegiatan mencapai tujuan. Berdasarkan pengertian di atas dapat 
diketahui bahwa pendidikan dan pelatihan sebagai upaya peningkatan dan pengembangan seseorang dalam organisasi kerja yang berguna dalam pencapaian tujuan organisasi.

Faktor-faktor yang mempengaruhi kepuasan kerja dan kinerja antara lain pelatihan dan karakteristik individu karyawan. Karakteristik individu merupakan ciri khas yang menunjukkan perbedaan seseorang tentang motivasi, inisiatif, kemampuan seseorang untuk tetap tegar menghadapi tugas sampai tuntas atau memecahkan masalah, menyesuaikan diri dengan lingkungan yang dapat mempengaruhi hasil kinerja individu. Seseorang sangat dipengaruhi oleh karakteristik individunya baik ketika sebagai manajer ataupun sebagai bawahan untuk memberikan konstribusi dalam pengambilan keputusan dan bertindak berkaitan dengan kinerja organisasi (Leonard et al., 2004). Karakteristik individu terdiri dari kapasitas belajar, kemampuan dan keterampilan, latar belakang keluarga, umur, jenis kelamin dan pengalaman (Gibson et al., 1996).

Peningkatan kinerja perlu diperhatikan pada perusahaan daerah seperti perusahaan daerah perkebunan Kabupaten Jember. Perusahaan daerah perkebunan Kabupaten Jember adalah badan usaha milik daerah dan menjadi andalan pemerintah Kabupaten Jember. Hal ini disebabkan sebagai penopang pendapatan asli daerah Kabupaten Jember. Kontribusi laba dari perusahaan daerah perkebunan Kabupaten Jember ke pendapatan asli daerah Kabupaten Jember beberapa tahun terakhir ini mengalami penurunan disebabkan hasil produksi komoditas perkebunan semakin menurun.

\begin{tabular}{llrrrrr}
\hline & & \multicolumn{5}{c}{ Tahun } \\
\cline { 3 - 7 } No & $\begin{array}{c}\text { Komo } \\
\text { diti }\end{array}$ & 2008 & 2009 & 2010 & 2011 & 2012 \\
\hline 1 & Karet & 1.518 .6 & 1.589 .7 & 1.460 .37 & 1.484 .03 & 1.453 .42 \\
& & 98 & 81 & 3 & 5 & 0 \\
2 & Kopi & 1.266 .6 & 1.238 .3 & 1.232 .19 & 459.946 & 1.043 .46 \\
& & 53 & 10 & 0 & & 7 \\
3 & $\begin{array}{l}\text { Kaka } \\
\text { o }\end{array}$ & 48.251 & 65.603 & 26.327 & 19.621 & 21.197 \\
4 & $\begin{array}{l}\text { Ceng } \\
\text { keh }\end{array}$ & 6.404 & 28.927 & 31.448 & & 2.132 \\
\hline
\end{tabular}

Tabel 1 Realisasi produksi tahun 2008-2012 PDP Jember

Sumber: PDP Jember Tahun 2013

Karyawan perusahaan daerah perkebunan Kabupaten Jember berjumlah 624 orang, dengan karyawan sebanyak itu mengakibatkan beban perusahaan daerah perkebunan Kabupaten Jember semakin berat dalam hal pembayaran gaji yang sudah menjadi kewajiban perusahaan pada setiap bulannya. Pimpinan perusahaan daerah perkebunan Kabupaten Jember dalam hal ini harus mengoptimalkan kemampuan dan keterampilan karyawan sehingga penempatan karyawan sesuai dengan pendidikan dan bidang pekerjaannya. Penambahan program pelatihan pada perusahaan daerah perkebunan Kabupaten Jember dapat meningkatkan kinerja, keahlian serta keterampilan dalam melaksanakan pekerjaan untuk meningkatkan pendapatan perusahaan. Program pelatihan yang dilakukan perusahaan daerah perkebunan Kabupaten Jember masih sangat kurang. Pelatihan yang dilaksanakan perusahaan daerah perkebunan Kabupaten Jember mulai dari tahun 2008 sampai dengan 2014 hanya sebanyak 5 kali, oleh karena itu program tersebut harus lebih ditingkatkan. Selama ini karyawan kurang keterampilan dan keahlian dalam pengelolaan kebun serta pengoperasionalan mesin untuk meningkatkan hasil produksi komoditas perkebunan. Penelitian ini mencoba untuk meneliti faktor-faktor yang berkaitan dengan kinerja karyawan antara lain pelatihan, karakteristik individu dan kepuasan kerja. Karyawan perusahaan daerah perkebunan Kabupaten Jember sebagian besar berpendidikan SD, SMP, dan SMA sehingga memerlukan pelatihan untuk meningkatkan keterampilan dan keahlian dalam mengelola kebun.

Tabel 2 Tingkat pendidikan karyawan perusahaan daerah perkebunan Kabupaten Jember tahun 2013

\begin{tabular}{lcccccc}
\hline \multirow{2}{*}{ Kebun/Lokasi } & \multicolumn{6}{c}{ Tingkat Pendidikan } \\
\cline { 2 - 7 } & SD & $\begin{array}{c}\text { SM } \\
\text { P }\end{array}$ & $\begin{array}{c}\text { SM } \\
\text { U }\end{array}$ & $\begin{array}{c}\text { Diplom } \\
\text { a }\end{array}$ & PT. & Jumlah \\
\hline Kantor Direksi & 2 & 3 & 11 & 5 & 33 & 54 \\
Sumber Wadung & 60 & 50 & 49 & 6 & 7 & 172 \\
Kali Mrawan & 31 & 17 & 12 & 6 & 4 & 70 \\
Gunung Pasang & 35 & 38 & 36 & 6 & 6 & 121 \\
Ketajek & 15 & 9 & 18 & 4 & 2 & 48 \\
Sumber Pandan & 53 & 20 & 25 & 4 & 4 & 106 \\
SumberTenggulu & 18 & 12 & 18 & 2 & 3 & 53 \\
n & 21 & 149 & 169 & 33 & 59 & 624 \\
\hline Jumlah & 4 & & \multicolumn{7}{c}{} \\
\hline Sumber : Kantor & PDP & Kabupaten Jember & Tahun \\
2013 & \multicolumn{7}{c}{}
\end{tabular}

Rumusan masalah penelitian antara lain: 1) apakah pelatihan berpengaruh terhadap kinerja karyawan PDP Jember?; 2) apakah pelatihan berpengaruh terhadap kepuasan kerja karyawan PDP Jember?; 3) apakah karateristik individu berpengaruh terhadap kepuasan kerja karyawan PDP Jember?; 4) apakah karakteristik individu berpengaruh terhadap kinerja karyawan PDP Jember? dan 5) apakah kepuasan kerja berpengaruh terhadap kinerja karyawan PDP Jember?

Penelitian ini dilakukan dengan tujuan: 1) menganalisis pengaruh pelatihan pada kinerja karyawan PDP Jember; 2) menganalisis pelatihan terhadap kepuasan kerja karyawan PDP Jember; 3) menganalisis pengaruh karakteristik individu terhadap kepuasan kerja karyawan PDP Jember; 4) menganalisis pengaruh karakteristik individu terhadap kinerja karyawan PDP Jember; 5) 
Wisnhu Githa, Ridwan I dan Tanti K, Pengaruh Dan Karakteristik Individu Terhadap Kepuasan Kerja Dan Kinerja Karyawan Perusahaan Daerah Perkebunan Jember

menganalisis kepuasan kerja terhadap kinerja karyawan PDP Jember.

Penelitian ini memiliki beberapa hipotesis antara lain: (H1) Pelatihan (X 1) berpengaruh positif terhadap kinerja karyawan(Y) perusahaan daerah perkebunan Kabupaten Jember.; (H2) Pelatihan (X 1) berpengaruh positif terhadap kepuasan kerja (Z) perusahaan daerah perkebunan Kabupaten Jember; (H3) Karakteristik individu (X 2) berpengaruh positif terhadap kepuasan kerja (Z) perusahaan daerah perkebunan Kabupaten Jember.; (H4) Karakteristik individu (X 2) berpengaruh positif terhadap kinerja karyawan (Y) perusahaan daerah perkebunan Kabupaten Jember.; (H5) kepuasan kerja berpengaruh signifikan dan positip terhadap kinerja karyawan PDP Jember.

Ruang lingkup penelitian ini dilakukan pada kantor PDP Kabupaten Jember. Penelitian ini hanya terbatas untuk meneliti faktor-faktor yang berkaitan dengan kepuasan dan kinerja karyawan antara lain pelatihan dan karakteristik individu.

\section{METODE PENELITIAN}

Penelitian ini termasuk dalam penelitian penjelasan (explanatory research) dan confimatory. Jenis dan sumber data menggunakan data primer dan data sekunder, data primer adalah data yang diperoleh langsung dari responden dan pimpinan instansi yang meliputi data tentang karyawan PDP Jember serta data sekunder, yaitu data yang diperoleh melalui pihak lain yang berkepentingan dan berkaitan dalam penelitian ini.

Lokasi penelitian yang dipergunakan dalam penelitian ini adalah PDP Jember. Populasi yang dimaksud dalam penelitian adalah seluruh karyawan PDP Jember. Karyawan yang dimaksud dalam populasi ini berjumlah 624 orang. Penelitian ini menggunakan jumlah sampel sebesar 160 orang (10 x 16 indikator). Teknik pengambilan sampel dalam penelitian ini adalah probability sampling dengan simple random sampling. Teknik ini digunakan bila populasi mempunyai anggota atau unsur yang homogen dan jumlah sampelnya diambil secara random sampling.

Variabel yang digunakan dalam penelitian ini adalah variabel eksogen pelatihan serta karakteristik individu, variabel endogen adalah kepuasan kerja dan kinerja. Kerangka pemikiran penelitian dijelaskan pada Gambar 1.

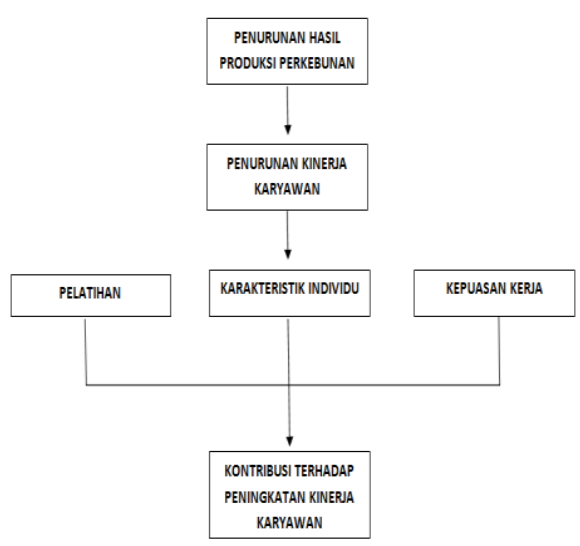

Gambar 1 Kerangka penikiran penelitian

Berdasarkan kerangka pemikiran penelitian ini maka diperoleh model penelitian yang dapat disajikan pada Gambar 2.

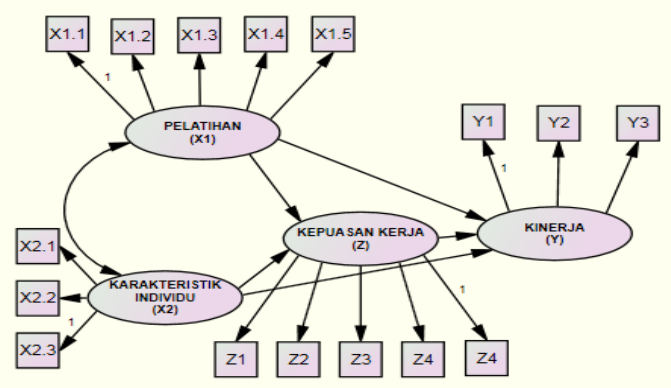

Gambar 2 Model penelitian

Keterangan :

$\mathrm{X} 1$ = Pelatihan

X11 = Pelaksanaan Pekerjaan

$\mathrm{X} 2=$ Karakteristik Individu

$\mathrm{X} 12=$ Perpindahan Tempat Kerja

$\mathrm{Z}$ = Kepuasan Kerja

X13 = Program Pelatihan

$\mathrm{Y}=$ Kinerja Karyawan

X14 = Manfaat Pelatihan

$\mathrm{X} 21$ = Kemampuan

$\mathrm{X} 15$ = Kesempatan Mengikuti Pelatihan

$\mathrm{X} 22=$ Sikap

$\mathrm{X} 23=$ Minat

Z 1 = Kepuasan terhadap Gaji

Z 2 = Kepuasan Melaksanakan Pekerjaan

Z 3 = Kepuasan terhadap Rekan Kerja

Z 4 = Kepuasan terhadap Promosi

Z $5=$ Kepuasan terhadap Atasan

Y 1 = Kuantitas Pekerjaan

Y 2 = Kualitas Pekerjaan

Y 3 = Ketepatan Waktu 
Analisis yang digunakan untuk menguji hipotesis dalam penelitian ini adalah model persamaan struktural (Structural Equation Modeling atau SEM) dengan menggunakan paket program AMOS (Analysis of Moment Structure) versi 18. Model persamaan struktural (SEM) adalah metode analisis yang digunakan dalam penelitian ini. Dalam SEM, ada dua kelompok analisis yang dilakukan secara bertahap, yaitu: (a) model pengukuran (measurement model) dan (b) model struktural (structural model). Secara umum, ada dua alat analisis utama dalam penelitian ini, yaitu: 1) alat uji asumsi SEM, dan 2) alat uji kecocokan model. Uji data yang telah terbukti valid dan reliabel pada tahap uji sebelumnya, dilakukan melalui ukuran-ukuran normalitas data secara univariat atau multivariat, Outlier (data yang berada di luar sebaran sebagian besar data), baik secara univariat maupun multivariat dan multikolinieritas. Beberapa uji goodness-of-fit model overall bersama dengan nilai cut-off-nya dapat dilihat pada Tabel 3.

Tabel 3 Pengujian goodness of fit model overall

\begin{tabular}{lcc}
\hline \multicolumn{1}{c}{ Kriteria } & $\begin{array}{c}\text { Nilai Cut- } \\
\text { Off }\end{array}$ & Keterangan \\
\hline Chi Square & $\begin{array}{c}\text { Diharapkan } \\
\text { kecil. Prob. } \\
>0,05\end{array}$ & Good Fit \\
\hline $\begin{array}{l}\text { Significance } \\
\text { Probability }\end{array}$ & $\geq 0,05$ & Good Fit \\
\hline RMSEA & $\leq 0,08$ & Good Fit \\
\hline GFI & $\geq 0,90$ & Good Fit \\
\hline AGFI & $\geq 0,90$ & Good Fit \\
\hline CMIN/DF & $\leq 2$ atau 3 & Good Fit \\
\hline TLI & $\geq 0,90$ & Good Fit \\
\hline CFI & $\geq 0,90$ & Good Fit
\end{tabular}

Sumber: Ferdinand (2006)

\section{HASIL DAN PEMBAHASAN}

Evaluasi asumsi SEM ini dibedakan atas empat macam, yaitu: ukuran sampel, uji outliers, uji normalitas dan multikolinieritas.

\section{a. Ukuran sampel}

Dalam pemodelan SEM ukuran sampel yang harus dipenuhi ada dua macam, yaitu ukuran sampel untuk estimasi ML harus minimal $10 \mathrm{x}$ jumlah variabel indikator yang diamati (Ferdinan 2002). Penelitian ini menggunakan 16 variabel indikator berarti jumlah sampel 10 × $16=160$ sampel. Jumlah sampel sebanyak 160 karyawan PDP dalam penelitian ini sudah memenuhi asumsi tentang jumlah sampel.

\section{b. Hasil uji outlier}

Hasil uji outliers pada penelitian nampak pada Malahanobis distance atau Mahalanobis $d$ squared. Dalam menghitung nilai Malahanobis distance berdasarkan nilai Chi squares pada derajat bebas $16 \mathrm{X} 4$ (jumlah variabel $\mathrm{X}$ indikator) pada tingkat $\mathrm{p}<0,05(\chi$ adalah sebesar 83,675 (berdasarkan tabel distribusi $\chi^{2}(16,0,05)$. Data yang memiliki jarak Mahalanobis distance lebih besar dari 83,675 adalah multivariate outlier. Hasil uji outlier penelitian menunjukkan 25,093 bahwa tidak ada satupun kasus yang memiliki nilai Malahanobis distance lebih besar dari 83,675 maka dapat disimpulkan tidak ada multivariate outlier dalam data penelitian.

\section{c. Uji normalitas}

Data variabel-variabel penelitian, seluruhnya memiliki nilai critical ratio yaitu memberikan nilai 1,530 terletak antara $-1,96 \leq \mathrm{CR}$ $\leq 1,96$. Hal ini membuktikan tidak terjadi pelanggaran asumsi normalitas SEM pada input data penelitian ini atau dikatakan bahwa data multivariate normal.

\section{d. Multikolinieritas}

Gejala multikolinieritas dapat diindikasikan dari determinan matriks varianskovarians data variabel eksogen. Nilai determinan yang kecil mengindikasi adanya gejala multikolinieritas. Apabila hal itu terjadi, maka data itu tidak dapat digunakan untuk penelitian (Ghozali 2007). Hasil uji menunjukkan bahwa nilai determinan matriks varians-kovarians = 1,070 jauh di atas nol dan dapat digunakan sebagai ukuran indikasi bahwa tidak terjadi multikolinieritas pada data yang dianalisis.

Model persamaan struktural yang dihasilkan dengan aplikasi Program AMOS versi 18.00, adalah dengan menghubungkan konstruk eksogen terhadap konstruk endogennya secara simultan. Seluruh indikator variabel yang terbukti valid dan reliabel digunakan seluruhnya dalam model. Hasil analisis data dapat disajikan pada Gambar 3.

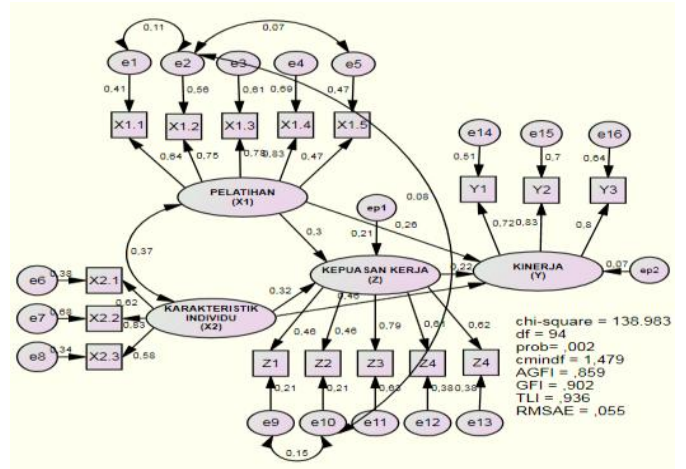

Gambar 3 Hasil pengujian SEM

Berdasarkan gambar 3 hasil pengujian SEM maka akan diperoleh nilai goodness of fit model overall sebagai berikut :

Tabel 4 Pengujian goodness of fit model overall 
Wisnhu Githa, Ridwan I dan Tanti K, Pengaruh Dan Karakteristik Individu Terhadap Kepuasan Kerja Dan Kinerja Karyawan Perusahaan Daerah Perkebunan Jember

\begin{tabular}{lrrc}
\hline \multicolumn{1}{c}{ Kriteria } & \multicolumn{1}{c}{$\begin{array}{c}\text { Nilai } \text { Cut- } \\
\text { Off }\end{array}$} & $\begin{array}{c}\text { Hasil } \\
\text { Perhitungan }\end{array}$ & Keterangan \\
\hline Chi Square & $\begin{array}{r}\text { Diharapkan } \\
\text { lebih kecil } \\
190,516\end{array}$ & 138,983 & Baik \\
Significance & $\geq 0,05$ & 0,002 & Marjinal \\
Probability & $\leq 0,08$ & 0,055 & Baik \\
RMSEA & $\geq 0,90$ & 0,902 & Baik \\
GFI & $\geq 0,90$ & 0,859 & Cukup Baik \\
AGFI & $\leq 2$ atau 3 & 1,479 & Baik \\
CMIN/DF & $\geq 0,95$ & 0,936 & Baik \\
TLI & $\geq 0,95$ & 0,950 & Baik \\
CFI & & & \\
\hline
\end{tabular}

Hasil pengujian hipotesis dari model SEM dijelaskan pada Tabel 5.

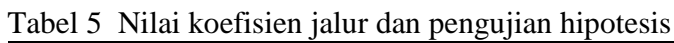

\begin{tabular}{lcccc}
\hline Variabel & $\begin{array}{c}\text { Koefis } \\
\text { ien } \\
\text { Jalur }\end{array}$ & $\mathbf{C . R}$ & Probabilitas & Ket. \\
\hline $\mathrm{X}_{1} \rightarrow \mathrm{Z}$ & 0,296 & 2,706 & 0,007 & Signifikan \\
$\mathrm{X}_{2} \rightarrow \mathrm{Z}$ & 0,322 & 2,773 & 0,006 & Signifikan \\
$\mathrm{X}_{1} \rightarrow \mathrm{Y}$ & 0,205 & 2,824 & 0,028 & Signifikan \\
$\mathbf{X}_{\mathbf{2}} \rightarrow \mathbf{Y}$ & $\mathbf{0 , 4 6 7}$ & $\mathbf{0 , 7 2 8}$ & $\mathbf{0 , 0 8 7}$ & $\begin{array}{c}\text { Tidak } \\
\text { Signifikan } \\
\text { Signifikan }\end{array}$ \\
$\mathrm{Z} \rightarrow \mathrm{Y}$ & 0,224 & 2,776 & 0,006 & \\
\hline
\end{tabular}

Hipotesis pertama menyatakan pelatihan (X1) berpengaruh signifikan terhadap kinerja karyawan (Y) perusahaan daerah perkebunan Kabupaten Jember berpengaruh signifikan dan positip. Hasil analisis data menunjukkan bahwa pelatihan (X1) memiliki nilai koefisien jalur sebesar 0,205 dengan nilai C.R sebesar 2,824. Nilai C.R ini lebih besar dari nilai C.R yang disyaratkan yakni sebesar 2. Berdasarkan hasil tersebut maka dapat disimpulkan pelatihan (X1) berpengaruh signifikan dan positip terhadap kinerja karyawan (Y). Hasil ini mendukung (diterima) pada hipotesis ketiga yang menyatakan pelatihan (X1) berpengaruh signifikan dan positip terhadap kinerja karyawan (Y) perusahaan daerah perkebunan Kabupaten Jember.

Hipotesis kedua dan ketiga dalam penelitian ini menyatakan bahwa pelatihan dan karakteristik individu berpengaruh signifikan dan positip terhadap kepuasan kerja karyawan telah terbukti. Berdasarkan Tabel 5 nilai koefisien jalur antara pelatihan (X1) terhadap kepuasan kerja (Z) adalah sebesar 0,296 dengan nilai C.R 2,706 lebih besar dari nilai kritis yang disyaratkan sebesar 2 . Variabel karakteristik individu (X2) terhadap kepuasan kerja (Z) memiliki nilai koefisien jalur sebesar 0,322 dengan nilai C.R sebesar 2,773 lebih besar dari nilai kritis sebesar 2 sebagaimana yang disyaratkan. Hasil ini mendukung (diterima) pada hipotesis kedua dan ketiga yang menyatakan pelatihan (X1) dan karakteristik individu (X2) berpengaruh signifikan dan positip terhadap kepuasan kerja (Z) pada karyawan perusahaan daerah perkebunan Kabupaten Jember.

Hipotesis keempat menyatakan karakteristik individu (X2) berpengaruh tidak signifikan dan negatip (ditolak) terhadap kinerja karyawan (Y). Hal ini ditunjukkan dengan nilai koefisien jalur karakteristik individu (X2) terhadap kinerja karyawan (Y) adalah sebesar 0,467 dan nilai C.R 0,728. Nilai C.R ini lebih kecil dari nilai kritis yang disyaratkan sebesar 2 .

Hipotesis kelima menyatakan bahwa kepuasan kerja (Z) berpengaruh signifikan dan positip terhadap kinerja karyawan (Y) perusahaan daerah perkebunan Kabupaten Jember. Berdasarkan hasil analisis nilai koefisien jalur kepuasan kerja (Z) terhadap kinerja karyawan (Y) sebesar 0,224 dengan nilai C.R 2,776. Nilai C.R ini lebih besar dari nilai kritis yang disyaratkan sebesar 2. Maka dapat disimpulkan bahwa kepuasan kerja karyawan (Z) berpengaruh signifikan dan positip terhadap kinerja karyawan (Y). Hasil ini mendukung (diterima) pada hipotesis kelima yang menyatakan bahwa kepuasan kerja (Z) berpengaruh signifikan dan positip terhadap kinerja karyawan (Y) perusahaan daerah perkebunan Kabupaten Jember.

\section{Implikasi Manajerial}

Penelitian ini mempunyai implikasi sangat penting bagi para pengambil kebijakan untuk meningkatkan kinerja karyawan perusahaan. Hasil analisis yang telah dilakukan untuk meningkatkan kinerja karyawan melalui variabel pelatihan serta karakteristik individu dapat dilakukan melalui pendekatan yaitu: 1) memprioritaskan peningkatan program pelatihan; 2) memperhatikan karakteristik individu karyawan; dan 3) meningkatkan kepuasan kerja. Hasil penelitian menunjukkan pelatihan dapat meningkatkan kinerja, sehingga elemen pelatihan harus dapat ditingkatkan lagi dengan jalan : 1) pimpinan senantiasa menjadwalkan atau mengatur kegiatan pelatihan secara terstruktur yang sesuai dengan komoditi tanaman pada setiap kebun 2) pimpinan memperhatikan karateristik individu karyawan terutama pada sikap, minat dan kemampuan karyawan 3) pimpinan perusahaan dapat meningkatkan gaji dan kesempatan promosi jabatan terhadap karyawan 4) pimpinan mampu memberikan visi dan misi yang mampu mendorong karyawan bekerja untuk kemajuan perusahaan. 


\section{SIMPULAN DAN SARAN \\ Simpulan}

Berdasarkan hasil penelitian yang dilakukan pada perusahaan daerah perkebunan Kabupaten Jember disimpulkan hal-hal sebagai berikut:

1. Pelatihan berpengaruh signifikan terhadap kinerja karyawan. Hasil penelitian menunjukkan bahwa semakin sering dilaksanakan pelatihan maka akan meningkatkan kinerja karyawan.

2. Pelatihan berpengaruh signifikan terhadap kepuasan kerja karyawan. Hasil penelitian menunjukkan bahwa semakin sering dilaksanakan pelatihan maka akan meningkatkan kepuasan kerja karyawan.

3. Karakteristik individu berpengaruh signifikan terhadap kepuasan kerja karyawan. Hasil penelitian menunjukkan bahwa semakin baik karakteristik karyawan baik kemampuan, sikap dan minat dalam pekerjaan akan meningkatkan kepuasan kerja karyawan.

4. Karakteristik individu tidak berpengaruh signifikan terhadap kinerja karyawan. Hasil penelitian menunjukkan bahwa semakin baik karakteristik individu belum tentu meningkatkan kepuasan kerja karyawan.

5. Kepuasan kerja berpengaruh signifikan terhadap kinerja karyawan. Penelitian menunjukkan bahwa semakin tinggi kepuasan kerja maka akan meningkatkan kinerja karyawan.

\section{Saran}

Berdasarkan pada hasil pembahasan dan kesimpulan penelitian ini, maka disarankan hal-hal sebagai berikut :

a. Bagi instansi dalam rangka meningkatkan kepuasan kerja dan kinerja karyawan secara berkesinambungan hendaknya perusahaan daerah perkebunan Kabupaten Jember memperhatikan faktor-faktor yang mempengaruhi seperti mengadakan program pelatihan yang berkesinambungan, pembinaan karakteristik individu karyawan dan juga melakukan evaluasi pelaksanaan pekerjaan. Selain itu perusahaan juga memperhatikan faktor-faktor internal yang mempengaruhi terhadap kinerja seperti gaji, kesempatan promosi jabatan, fasilitas dan budaya kerja sehingga kinerja karyawan semakin meningkat.

b. Variabel penelitian hendaknya ditambah dengan variabel penelitian lain supaya diperoleh hasil yang lebih akurat contohnya lingkungan kerja, motivasi, kompensasi dan lain-lain. Di samping itu juga memperluas sampel penelitian dengan membandingkan antar perusahaan daerah perkebunan lain sehingga hasil penelitian dapat digeneralisasi.

\section{DAFTAR PUSTAKA}

Ariyatiningsih. 2003. Keterkaitan antara Kepuasan Kerja Karyawan dan Kepuasan Pelanggan [tesis]. Surabaya: Program Pasca Sarjana Universitas Airlangga.

As'ad. M. 2004. Psikologi Industri. Yogyakarta: Liberty.

Baugmartener H, Homburg. 1996. Applications of Structural Equation Modeling in Marketing and Consumer Research. A review International Journal of Research in Marketing 3(1):139- 161.

Benhabib J, Spiegel M. 1994. The Role of Human Capital In Economic Development: Evidence From Aggregate Cross-Country Data. Journal of Monetary Economics 3(4):143-173.

Ferdinand A. 2002. Struktural Equation Modelling: dalam Penelitian Manajemen. Semarang: Badan penerbit Universitas Diponegoro.

Georgellis Y, Lange T. 2007. Participation In Continuous, On-The-Job Training And The Impact On Job Satisfaction: Longitudinal Evidence From The German Labour Market. International Journal of Human Resource Management 8(1):49-61.

Ghozali I. 2005. Amos Versi 16.0. Jakarta: Gramedia.

Gibson I, Donnely. 1996. Organisasi dan Manajemen. Alih Bahasa Djoerban Wahid. Surabaya (ID): Penerbit Erlangga.

Djati PS 2008. Dampak pergeseran nilai-nilai organisasi terhadap kebijaksanaan sumber daya manusia dan implikasinya. Jurnal Manajemen dan Kewirausahaan 2(1):9-18.

Leonard A, Robert L. 2004. Public Service Motivation and Organizational Citizenship Behavior in Korea. International Journal of Manpower 27(8): 722-740.

Mangkunegara . 2005. Manajemen Sumber Daya Manusia. Jakarta: Bumi Aksara Jakarta.

Mark CE, Kay L. 2001. Determinants Of Job Satisfaction Of Municipal Government. Journal State and Local Government Review 33(3):65-74.

Novita US, Eka AT. 2008. Pengaruh Karakteristik Individu, Komunikasi Efektif dan Kepuasan Kerja terhadap Kinerja Karyawan (Studi Pada Karyawan Tetap Pt. Tambang Batubara Bukit Asam) [tesis]: Fakultas Ekonomi Universitas Brawijaya,

Ranupandojo K, Hidjrachman, Husnan A. 1999. Manajemen Personalia, Edisi 4, Pustaka. Yogyakarta: Binawan Presindo FE - UGM. 
Wisnhu Githa, Ridwan I dan Tanti K, Pengaruh Dan Karakteristik Individu Terhadap Kepuasan Kerja Dan Kinerja Karyawan Perusahaan Daerah Perkebunan Jember

Rahman A. 2009. Hubungan sistem administrasi perpajakan modern dengan kepatuhan wajib pajak. Jurnal Ilmu Administrasi 6(1):119-138.

Robbins SP. 2003. Perilaku Organisasi. Jakarta: Indeks Kelompok Gramedia.

Rose A, Cleveland L. 2004. Tailored and Ongoing Training Can Improve Job Satisfaction. Margaret Blenkner Research Institute: IFAS

Schmidt SW. 2007. The Relationship Between Satisfaction with Workplace Training and Overall Job Satisfaction. Journal Human Resource Development Quarterly 18(4):112124.

Simamora H. 2003. Manajemen Sumber Daya Manusia. Cetakan Pertama. Yogyakarta: YKPN.
Subyantoro A. 2009. Karakteristik Individu, Karakteristik Pekerjaan, Karakteristik Organisasi dan Kepuasan Kerja Pengurus yang Dimediasi oleh Motivasi Kerja (Studi pada Pengurus KUD di Kabupaten Sleman). [tesis]: Fakultas Ekonomi UPN "Veteran" Yogyakarta.

Suyatno. 2002. Manajemen Sumber Daya Manusia. Jakarta: Gramedia Pustaka Utama.

Tsang H, Levin S. 1995. Job Satisfaction and Organizational Commitment in the Hongkong Fast-Food Industry. Emerald International Journal 2(4):176-191.

Utama, S. 1996. Prioritas Kebutuhan Staf Berdasar Karakteristik Individu Pengaruhnya Terhadap Keputusan Kerja [disertasi]. Surabaya: Program Pascasarjana Universitas Airlangga. 